\title{
ESCAVANDO TÚNELES: A DANZA NOS ALBORES DO SÉCULO XXI
}

Ana Abad Carlés

Membro do Núcleo de Estudios Antropológicos

sobre Danza, Movimiento y Sociedad

(IDAES-UNSAM)

Bos Aires 



\section{INTRODUCIÓN}

A carreira daquelas mulleres que participaron de forma creativa e artística, quer como creadoras, quer como axentes de creación no ámbito do ballet, foi lentamente eclipsada e, en moitos casos, esquecida. Diversos artigos aparecidos na prensa nos últimos anos cuestionan a ausencia de mulleres nos eidos de creación e poder, xa non só na esfera do ballet, senón no da danza en xeral (Garafola 2005, Higgins 2009, Mackrell 2009, Jennings 2013). Nesta breve exposición presentaranse algunhas cuestións que ter en conta á hora de abordar este tema e ofreceranse estatísticas, así como testemuños persoais, que axuden a entender e explicar algúns dos factores que contribuíron a esta mudanza no sector.

\section{U-LAS MULLERES?}

Cando se observa o acontecido nas artes ao longo do século xx, é doado recoñecer unha pauta no xeito en que as mulleres atoparon o seu camiño de forma lenta, mais obstinada, nos diferentes medios artísticos. O camiño é longo e difícil de seguir e a realidade amosa que, malia que as mulleres se introduciron de maneira importante nestes sectores profesionais, continúan a ser unha minoría nos seus postos de liderado. Na Gran Bretaña, o Cultural Leadership Programme (CLP) decidiu realizar un estudo co que poder dar cifras reais á situación actual das artes deste país e descubriu que, por cada líder feminina no sector, había 2,5 líderes masculinos (Carty 2010).

No ballet, e na danza en xeral, as mulleres fóronse facendo cada vez máis invisibles conforme avanzaba o século, ata case desapareceren da escena. A compracencia con que este feito foi recibido é cando menos preocupante.

Virginia Woolf foi quizais unha das mulleres que mellor articularon a situación destas, non só nas artes, senón no campo profesional en xeral. A súa obra 
A Room of Onés Own (Un cuarto de seu) (1929) é unha longa reflexión sobre o papel da muller no seu tempo, pensamento que se estendería a gran parte da súa obra literaria. Woolf comprendeu coma poucas persoas a importancia de entender o noso pasado:

Non podemos comprender o presente se o separamos do pasado. Se queremos entender o que estamos a facer agora [...] debemos esquecer que somos, por agora, nós mesmas. Debemos converternos na xente que fomos hai dúas ou tres xeracións ${ }^{1}$. (Woolf 1978: 8)

Para comprender a realidade actual é necesario pensar no destino que tiveron esas xeracións de coreógrafas que abriron e continuaron camiños durante o s. Xx. Ao mesmo tempo que a súa carreira e obras desaparecían das páxinas da historia, a súa posición como modelos para as futuras xeracións foi perdendo forza. Quizais os seus camiños non fosen continuados polas xeracións actuais ao se esqueceren os seus puntos de vista e as súas posicións dentro do contexto da danza do século pasado.

Estes son tempos de corrección política nos que ás mulleres occidentais se nos lembra decontino que temos igualdade de oportunidades. No entanto, a realidade demostra que as mulleres non posúen a representación que teñen os homes nos postos de poder e decisión. Outro recente estudo realizado por Skillset no Reino Unido demostra que, neste país, «as mulleres teñen moita menor representación e están moito peor pagas nas industrias creativas e culturais» (Arts Professional 2010: 2). A diferenza en salarios é dun $20 \%$ menos, malia que «un $93 \%$ das empregadas teñen unha licenciatura, comparado cun $78 \%$ dos homes» (íd.). Outro estudo realizado por Arts Council England tamén recollía datos como o feito de «só un $25 \%$ dos teatros estaren dirixidos por directoras artísticas» $»^{2}$ (íd.).

A maioría das compañías de ballet estiveron dirixidas por homes durante as últimas dúas décadas. Cando Assis Carreiro, directora de Dance East ${ }^{3}$, organizou

\footnotetext{
${ }^{1}$ "We cannot understand the present if we isolate it from the past. If we want to understand what it is that [we] are doing now [...] [we] must forget that we are, for the moment, ourselves. We must become the people that we were two or three generations ago».

${ }^{2}$ "Women are sorely under-represented and underpaid across the creative and cultural industries [...] 93\% of female employees holding a degree compared to $78 \%$ of men [...] just $25 \%$ of theatres are run by female artistic directors».

${ }^{3}$ Dance East é unha das axencias nacionais de danza do Reino Unido.
} 
nos anos 2003 e 2005 os seus primeiros Rural Retreats para directores de compañías de ballet, os números indicaban que, dos 26 directores de compañías que representaron 15 países no retiro do ano 2005, 19 eran homes. Dos outros 18 que foran invitados, mais que non puideron asistir, todos eran homes (Dance East 2005). O retiro do ano 2005, «Ballet into the $21^{\text {st }}$ Century» ( $\mathrm{O}$ ballet no s. XXI»), amosaba unha realidade clara: das 44 compañías de ballet representadas, só seis tiñan unha muller como directora.

Gráfico 1: Dance East, Rural Retreats: Ballet into the $21^{\text {st }}$ Century (2005). Dirección das compañías de ballet

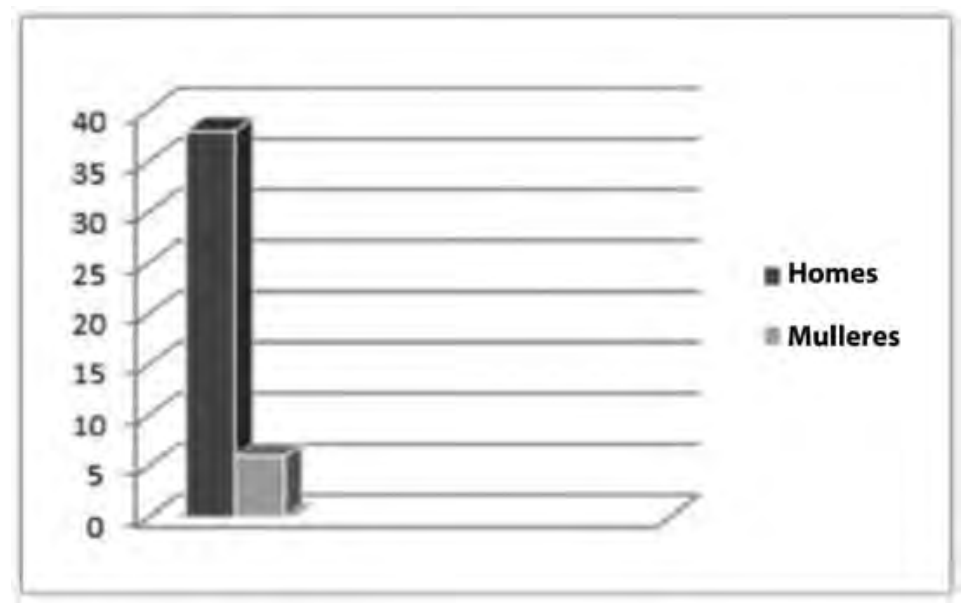

Nunha mesa redonda organizada por Dance Umbrella e Dance UK no ano 2009, a xornalista e crítica Judith Mackrell comentaba os seguintes datos: en 2008, das 59 compañías importantes de danza estadounidenses, 45 estaban dirixidas por homes, 10 por mulleres e as restantes catro estaban dirixidas por un equipo de home e muller. De igual xeito, ao se examinaren as subvencións outorgadas polo National Endowment for the Arts en 2008, as cifras indicaban que, dos 18 coreógrafos que recibiran subvencións, 13 eran homes, cunha media de subvención de 10000 dólares, mentres que a subvención media recibida polas mulleres era de 5000 dólares (Dance Umbrella 2009). 
Gráfico 2: Dirección das principais compañías de danza nos EUA e subvencións do NEA para coreografía (2008)

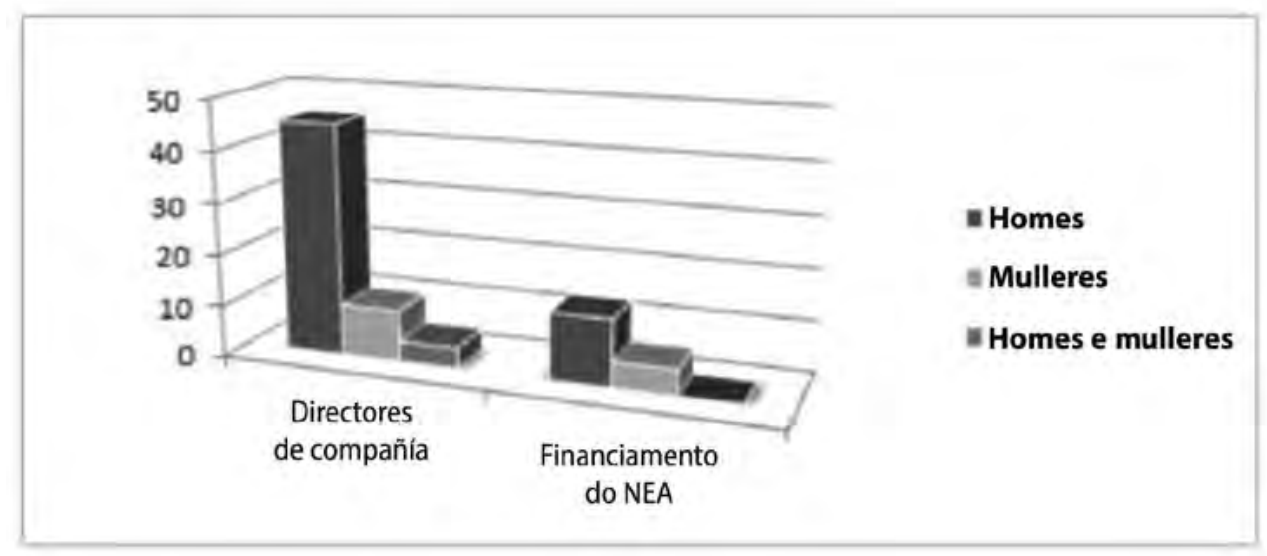

Cando se examina o novo repertorio creado durante este tempo, semella haber un desequilibrio entre as obras creadas por homes e por mulleres. Porén, as rapazas estudan coreografía en moito maior número ca os rapaces ${ }^{4}$. Cando nunha ocasión tivemos a oportunidade de mandar unha pregunta sobre as posibles causas polas que existe unha escaseza de coreógrafas a unha entrevista aberta con Nacho Duato, director daquela da Compañía Nacional de Danza, retransmitida pola Cadena SER, a súa resposta foi a seguinte: «Non sei, mais obviamente non se debe á falta de talento con respecto aos homes» (Duato 2003).

A opinión de Duato, malia demostrar un alto grao de empatía coa situación, quedaba moi afastada da realidade visible da Compañía Nacional de Danza, que, nese mesmo ano de 2003, de entre un repertorio de máis de cincuenta obras, tiña tan só unha creada por unha muller: Trece gestos del cuerpo (1987), de Olga Roriz. Sete anos despois, a compañía incrementou o seu repertorio a noventa obras, de entre as cales unicamente outra obra, Nasciturus (2003), de Yoko Taira, fora creada por unha muller. Isto deixaba unha porcentaxe de produción feminina na Compañía Nacional de Danza do 2,2 \% durante a época de Duato como direc-

\footnotetext{
${ }^{4}$ Ver o artigo "Invisible Women», de Susan Crow. É a nosa propia experiencia tamén tras estudarmos coreografía en diferentes institucións e a diverso nivel. Como profesora de coreografía na actualidade, debo dicir que a situación non mudou. Dos 18 alumnos do curso de licenciatura en danza profesional e musicais (2009-2010) en The Urdang Academy (Londres), só un terzo eran rapaces.
} 
tor (Compañía Nacional de Danza de España 2011). Se o talento das mulleres é realmente igual ao dos homes, como é posible que a creación feminina fose tan escasa dentro da compañía durante tan longo tempo?

Cathy Marston é unha das poucas mulleres que traballa como coreógrafa de ballet nestes momentos. Cando lle formulamos a mesma pregunta ca a Duato, daba razóns moi diferentes á hora de explicar a falta de coreógrafas que traballaban na actualidade: «[S]er bailarina de ballet é moi competitivo. É difícil ser bailarina e coreógrafa ${ }^{5}$ (Marston 2003). Este punto de vista da incompatibilidade de bailar e coreografar ao mesmo tempo estaba apoiado tamén por Susan Crow, exbailarina do Royal Ballet e coreógrafa, cando explicaba:

Creo que ten que ver co traballo [...]. [A] última vez que alguén me preguntou isto foi en 1989 [...] e unha das cousas que dixen daquela era que hai algo que se ten que ter en consideración e é un problema práctico, e é que, co repertorio clásico, as mulleres teñen que traballar máis, e por isto teñen menos tempo ${ }^{6}$. (Crow 2003)

Outra razón na que tanto Crow como Marston coincidían era un aspecto moito máis intanxible e que afecta á educación e desenvolvemento das bailarinas de ballet. $\mathrm{O}$ coidar e educar (nurture) semella ser un termo chave no que ambas as coreógrafas coincidían; a necesidade de ser coidada e educada ou de coidar e educar a outros. Parece coma se no centro da educación feminina na danza quedase esta necesidade enraizada na propia cultura institucional e que pasou a formar parte do desenvolvemento psicolóxico das alumnas de ballet: «[M] esmo se teñen creatividade, elas queren que o seu desenvolvemento se faga a través dos homes» ${ }^{7}$ (Marston 2003).

Dun xeito semellante, e dando un exemplo dunha xeración anterior, Susan Crow formulaba a cuestión de se esta necesidade de coidar era unha característica feminina pola que «[se nos desvía] cara ao coidado do desenvolvemento dunha compañía [...] [e] doutros bailaríns antes que crear obras propias? [...] Non sei» ${ }^{8}$ (Crow 2003).

${ }^{5}$ «[...] it's very competitive to be a ballet dancer. It's difficult to be a ballet dancer and a choreographer».

${ }^{6}$ «I think it has to do with the work [...]. [T] he last time I was asked this question was in 1989 [...] and one of the points that I made then was that there is something that one has to bear in mind and it is a very practical problem and it is that with the classical repertoire, the women are working harder, so then they have less time».

7 «[...] even if they've got creativity, they want to be nurtured by men».

8 «[...] to get diverted into the nurturing of a company [...] [and] other dancers rather than to make their own work? [...] I don't know». 
Esta non é unha noción nova; varios estudos de psicoloxía realizados por Jeanne Block en 1984 e recollidos por Hilary M. Lips cando analizaba a falta de poder das mulleres nos ámbitos institucionais chegaban a unha conclusión semellante: «ás rapazas — comentaba — animábanas a botar raíces, aos rapaces aprendíanlles a botar ás» ${ }^{9}$ (Lips 1994: 90).

Outro aspecto importante mencionado por Crow e moi particular no medio do ballet ten que ver coa dificultade de poder desenvolver unha forte personalidade individual no marco dunha compañía «que baila o repertorio tradicional, onde sempre hai un gran corps de ballet de mulleres [...]. [H] ai unha especie de opresión determinada por este corps de ballet e que exerce moita presión sobre as mulleres no ballet á hora de se axustaren a certo prototipo, principalmente pola competición ${ }^{10}$ (Crow 2003).

Semella que as razóns prácticas e psicolóxicas que poñen obstáculos a que calquera muller adopte a carreira coreográfica son diversas. Como se explicou, se a coreógrafa xorde dentro dunha compañía de ballet institucionalizada, os requirimentos desta arredor da necesidade de a coreógrafa bailar o repertorio clásico dificultan de máis que a creadora realice as súas obras. É certo que tanto Bronislava Nijinska como Ninette de Valois conseguiron facelo, mais as presións en materia técnica hoxe en día son moito maiores. Se a coreógrafa desenvolve o seu interese coreográfico noutro marco, daquela existe unha dificultade engadida á hora de realizar a transición dunha carreira como intérprete a coreógrafa. A meirande parte dos bailaríns masculinos dan este paso cando están na trintena. Para a maioría das mulleres, se planean a fin da súa carreira como bailarinas a esta idade, está a presión biolóxica de empezaren unha familia (Marston 2003). Deste xeito, a maternidade dalgunha maneira convértese no feito fundamental no momento da transición profesional na que a maioría dos coreógrafos comezan a súa carreira ${ }^{11}$.

Mesmo no caso de a carreira como coreógrafa se iniciar, as dificultades de atopar subvencións, financiamento etc. realmente complican a supervivencia na

\footnotetext{
9 "[...] girls, she said, were encouraged to develop roots, boys were taught to develop wings».

${ }^{10}$ "[...] the difficulty of developing a strong individual personality within the framework of a classical ballet company "that dances the traditional repertoire, where there's always a very large corps de ballet of women [...] that there's a kind of oppression that the corps de ballet requires and that there is a tremendous amount of pressure on women in ballet to conform to certain mould, because of the competition"”.

${ }^{11}$ Bronislava Nijinska e Twyla Tharp foron nais e coreógrafas, mais as demandas de coidar un bebé estaban en oposición constante coas necesidades da súa profesión. Tharp, en especial, explicaba todo isto na súa autobiografía Push Comes to Shove (1992).
} 
profesión. Obviamente, este non é un problema endémico na esfera feminina, nin tan sequera específico da danza, posto que afecta a todo o mundo artístico. Porén, poida que todas estas dificultades lle dean á artista algo máis en que pensar á hora de considerar un futuro profesional no eido da coreografía.

Mais, se ben todos estes obstáculos de índole práctica e psicolóxica poden explicar que moitas mulleres decidan non asumir o papel de coreógrafas, aínda non fica moi clara a case total ausencia de mulleres que se dediquen á coreografía na actualidade.

\section{O MITO DA «PIONEIRA»: ESCAVANDO TÚNELES}

Resulta sorprendente que Cathy Marston sentise, ao falar da súa carreira, que estaba «escavando túneles para as xeracións futuras». "Estou abrindo vieiros» ${ }^{12}$ (Marston 2003).

A utilización do termo "pioneira» en referencia ao traballo de calquera coreógrafa debería ser posto en cuestión. Se "pioneira» é aquela persoa que abre vieiros para as xeracións futuras, daquela Marie Sallé sería a "pioneira» das mulleres coreógrafas xa no s. XviII (Abad Carlés 2013). No entanto, parece coma se, sempre que unha muller empeza unha carreira que non está asociada ao seu sexo, se convertese nunha pioneira, malia o número de mulleres que xa ocuparan eses postos con anterioridade ao longo da historia.

É unha situación complexa, mais non semella que sexa unha coincidencia. Se as mulleres ou os homes posúen modelos, calquera tipo de modelo, é máis doado seguilos como exemplos ou, polo menos, ver con normalidade o papel e a posición que representan. Se non se ten un modelo ou exemplo que seguir, comeza un camińo que está máis relacionado coa figura de Isadora Duncan: unha figura solitaria que tenta atopar o seu lugar nun medio artístico hostil. Máis unha vez, a artista ha de "escavar un túnel» que, malia ter sido escavado moitas veces con anterioridade, volveu ser tapado tan pronto como chegou ao seu final. O sentido de continuidade histórica desaparece e á muller tócalle empezar de novo desde o principio. Seguindo aquelas palabras xa citadas doutra gran "pioneira», Martha Graham, «ela ten que atopar o seu propio baile» (Tharp 1992: 78). Abofé, esta

${ }^{12}$ «[...] burrowing the tunnel for future generations. I'm forwarding the path». 
premisa adoita traer consigo a creación de obras de grande orixinalidade, pero igualmente dificulta de máis o proceso de aprendizaxe. Realmente resulta difícil imaxinar a Balanchine atopando o seu propio baile e desbotando o seu pasado nos Teatros Imperiais. De feito, Twyla Tharp, quen si seguiu o principio recollido por Graham, actualmente dá aos futuros artistas un consello moi diferente: «Cariño, fíxose todo xa. Non hai nada realmente orixinal. Nin Homero nin Shakespeare e obviamente ti tampouco. Acéptao»" ${ }^{13}$ (Tharp 2003: 22).

É moi difícil enunciar con certeza e dentro dun aparato metodolóxico concreto a causa pola que a tradición coreográfica feminina chegou a esta pausa. Quizais non é posible atopar unha resposta dentro dos límites impostos pola actual forma de abordar a evidencia histórica e a súa avaliación. Como Susan Bennett comentou: «[M]alia saberse efectivamente que se ten que facer outro tipo de traballo, o método historiográfico tira da nosa historia dun xeito inevitable - mesmo das nosas historias alternativas- e pona na traxectoria do que xa se cońeceu $»^{14}$ (Gale e Gardner 2000: 53).

Semella que existe un consenso xeral no mundo das artes arredor da cuestión da creatividade feminina e a necesidade urxente de facer algo ao respecto, aínda que só sexa por salvagardar figuras que sirvan como modelos para as xeracións presentes e futuras. Esta cuestión ha de traer consigo novas formas de investigación e novas preguntas sobre a validez con que ata agora se mantiveron certos criterios, regras e xuízos considerados sagrados. Algúns permanecerán, mais algúns deberán reaxustarse. Poida que non sexa doado atopar unha conexión entre a perda coreográfica que afectou ao repertorio de ballet nos últimos anos e o sexo dos artistas que crearon as obras. Porén, si semella haber unha conexión entre tal perda e a situación actual neste medio artístico. Novas preguntas xorden arredor deste tema: por que a situación da muller retrocedeu tanto no ámbito do ballet e da danza en xeral nos últimos decenios? Cales foron as causas que levaron as mulleres a unha situación de profundo mutismo nunha arte que crearon e que sostiveron durante décadas? Houbo outros factores de tipo sociocultural que ata agora permaneceron ausentes do discurso teórico e que fixeron que, na época de aparentes políticas de igualdade entre homes e mulleres, estas perdan un territorio no que se vińan movendo, na aparencia, con facilidade?

\footnotetext{
${ }^{13}$ «Honey, it's all been done before. Nothing's really original. Not Homer or Shakespeare and certainly not you. Get over yourself».

14 «[...] despite knowing that there is other work to be done, historiographic method inevitably pulls our history - even our alternative histories - back into the trajectory of what has always already been known».
} 
Ann Daly lembraba a Albert Einstein e a súa crenza en que a formulación de problemas é máis esencial ca a súa solución, xa que as respostas chegan co tempo e o realmente importante é a creación de novas preguntas que nos fagan repensar as nosas propias ideas e metodoloxías: «Porque nunca se van producir novas formas de cońecemento e de mirar e comprender se se seguen a facer as mesmas preguntas» ${ }^{15}$ (Daly 1998: 79).

${ }^{15}$ «For new knowledge or new ways of looking and understanding will never be produced if the same old questions keep getting asked». 


\section{REFERENCIAS BIBLIOGRÁFICAS}

AвAD CARlÉs, Ana (2013): Coreógrafas, directoras y pedagogas: la contribución de la mujer al desarrollo del ballet y el cambio de paradigma en la transición al s. XXI. Tese de doutoramento. València, Universitat Politècnica.

Arts Professional (2010): «The Second Sex?», Arts Professional, 227, 2.

Burns, Susanne / Sue Harrison (2009): Dance mapping: a window on dance, 2004-2008, Londres, Arts Council England.

Carty, Hilary (2010): «Leading women», Arts Professional, 228, 7.

Compañía Nacional de Danza de España (2011 [última actualización]): Repertorio (http://cndanza.mcu. es/esp/repertorio/repertorio.htm) [última consulta: xuño, 2011].

Crow, Susan (2002 [última actualización]): «Invisible Women» (http://Londresdance.com/articles/ features/invisible-women/) [última consulta: xuño, 2011].

Crow, Susan / Jennifer JaCKson (2002 [última actualización]): BIG Discussion: The Role of the Artistic Director (http://www.ballet.co.uk/magazines/yr_02/nov02/big_on_the_ad_0101.htm) [última consulta: xuño, 2011].

DAly, Ann (1998): «Woman, Women, and Subversion: Some Nagging Questions from a Dance Historian», Choreography and Dance, 5:1, 79-86.

Dance East (2015): Rural Retreats: Ballet into the $21^{\text {st }}$ Century, Ipswich, Dance East.

Gale, Maggie B. / Viv Gardner (eds.) (2000): Women, Theatre and Performance: New Histories, New Historiographies, Manchester, Manchester University Press.

Garafola, Lynn (2005): Legacies of Twentieth-Century Dance, Middletown, CT, Wesleyan University Press. Higgins, Charlotte (2009 [última actualización]): «Dance World 'failing to celebrate women'», The Guardian, 11-5-2009 (http://www.guardian.co.uk/stage/2009/may/11/dance-choreographers-womensadlers-wells?INTCMP=SRCH) [última consulta: xuño, 2011].

JENNINGs, Luke (2013 [última actualización]): «Sexism in dance: where are all the female choreographers?», The Guardian, 28-4-2013 (http://www.guardian.co.uk/stage/2013/apr/28/women-choreographers-glassceiling) [última consulta: xuño, 2013].

Lips, Hilary M. (1994): «Female Powerlessness: A Case of “Cultural Preparedness”?», en H. Lorraine Radtke / Henderikus J. Stam (eds.), Power/Gender: Social Relations in Theory and Practice, Londres/Thousand Oaks/Nova Delhi, SAGE Publications, 89-107.

Mackrell, Judith (2009 [última actualización]): «The ladies vanish», The Guardian, 13-5-2009 (http:// www.guardian.co.uk/stage/2009/may/13/dance-sadlers-wells-southbank) [última consulta: xullo, 2011].

Mackrell, Judith (2009 [última actualización]): «Vanishing pointe: where are all the great female choreographers?», The Guardian, 27-10-2009 (http://www.guardian.co.uk/stage/2009/oct/27/where-arethe-female-choreographers) [última consulta: agosto, 2011].

SKILlset (2010): Women in the Creative Media Industries, Londres, Skillset.

Tharp, Twyla (1992): Push Comes to Shove, Nova York, Bantham Books.

Tharp, Twyla (2003): The Creative Habit: Learn It and Use It for Life, Nova York, Simon \& Schuster.

Woolf, Virginia (1929 [2009]): A Room of One's Own, Adelaide, South Australia, University of Adelaide (http://ebooks.adelaide.edu.au/w/woolf/virginia/w91r/index.html) [última consulta: xullo, 2011]. 


\section{Material aUdiovisual}

Dance Umbrella (2009): Where Are the Women? (presentado por Judith Mackrell) [gravación sonora en liña en formato MP3], Londres, Dance UK.

MacGibbon, Ross (2001): Bourne to Dance [gravación de televisión en vídeo], Londres, Channel Four.

\section{COMUNICACIÓN PERSOAL}

Crow, Susan (2003): entrevista con Ana Abad Carlés, Londres, Royal Festival Hall.

DuATo, Nacho (2003): Entrevista Abierta, 24-11-2003 (www.cadenaser.es).

Marston, Cathy (2003): entrevista con Ana Abad Carlés, Londres, Royal Opera House. 